\title{
Delineating the Role of Various Factors in Renal Disposition of Digoxin through Application of Physiologically Based Kidney Model to Renal Impairment Populations ${ }^{[\sqrt{[}}$
}

\author{
Daniel Scotcher, Christopher R. Jones, ${ }^{1}$ Aleksandra Galetin, and Amin Rostami-Hodjegan
}

Centre for Applied Pharmacokinetic Research, School of Health Sciences, University of Manchester, Manchester, United Kingdom (D.S., A.G., A.R.-H.); DMPK, Oncology iMed, AstraZeneca R\&D, Alderley Park, Macclesfield, Cheshire, United Kingdom (C.R.J.); and Simcyp Limited (a Certara Company), Blades Enterprise Centre, Sheffield, United Kingdom (A.R.-H.)

Received August 25, 2016; accepted December 20, 2016

\begin{abstract}
Development of submodels of organs within physiologicallybased pharmacokinetic (PBPK) principles and beyond simple perfusion limitations may be challenging because of underdeveloped in vitro-in vivo extrapolation approaches or lack of suitable clinical data for model refinement. However, advantage of such models in predicting clinical observations in divergent patient groups is now commonly acknowledged. Mechanistic understanding of altered renal secretion in renal impairment is one area that may benefit from such models, despite knowledge gaps in renal pathophysiology. In the current study, a PBPK kidney model was developed for digoxin, accounting for the roles of organic anion transporting peptide 4C1 (OATP4C1) and $\mathrm{P}$-glycoprotein $(\mathrm{P}-\mathrm{gp})$ in its tubular secretion, with the aim to investigate the impact of age and renal impairment (moderate to
\end{abstract}

severe) on renal drug disposition. Initial PBPK simulations based on changes in glomerular filtration rate (GFR) underestimated the observed reduction in digoxin renal excretion clearance $\left(C_{\mathrm{R}}\right)$ in subjects with moderately impaired renal function relative to healthy. Reduction in either proximal tubule cell number or the OATP4C1 abundance in the mechanistic kidney model successfully predicted $59 \%$ decrease in digoxin $\mathrm{CL}_{R}$, in particular when these changes were proportional to reduction in GFR. In contrast, predicted proximal tubule concentration of digoxin was only sensitive to changes in the transporter expression/ million proximal tubule cells. Based on the mechanistic modeling, reduced proximal tubule cellularity and OATP4C1 abundance, and inhibition of OATP4C1-mediated transport, are proposed as possible causes of reduced digoxin renal secretion in renally impaired patients.

\section{Introduction}

Dosage adjustment is often required in patients with impaired renal function because of the impact this condition may have in altered drug clearance through either decreased renal excretion alone or in combination with reduced metabolism. Ideally, such decisions on dosage adjustment will be supported by recommendations on drug labels that are currently based on statistical analyses of clinical data, often from dedicated but small sized studies (US Food Drug Admin, 2010; Matzke et al., 2011; European Medicines Agency, 2014). The pharmaco-statistical nature of the analysis limits the ability to extrapolate findings beyond the boundaries of the patient groups originally studied. A direct consequence of this, in conjunction

D.S. was supported by a $\mathrm{PhD}$ studentship from the Biotechnology and Biological Sciences Research Council UK (BB/J500379/1) and AstraZeneca, Cambridge, UK

${ }^{1}$ Current afiliation: Heptares Therapeutics Limited, BioPark, Welwyn Garden City, Hertfordshire, UK

dx.doi.org/10.1124/jpet.116.237438

S This article has supplemental material available at jpet.aspetjournals.org. with paucity of data in severe renal impairment, has been the large proportion of drug labels void of any recommendations in the most vulnerable renal impairment patients according to recent survey of labels for drugs approved by the Food and Drug Administration in 2013 and 2014 (Jadhav et al., 2015).

A possible solution is the use of physiologically based pharmacokinetic (PBPK) models with embedded organ models that incorporate mechanisms of local disposition. However, these models require careful separation of the drug, system and trial design (Rowland et al., 2011; Rostami-Hodjegan, 2012). In addition, PBPK modeling approaches require case examples to build certainty in their performance. Relatively strong confidence is now placed on the application of PBPK modeling when cytochrome P450 (CYP)-mediated metabolism is the dominant route of elimination by many investigators, including, but not restricted to, the regulatory agencies (Wagner et al., 2015). Conversely, despite recent efforts, evidence for the applicability of PBPK for the prediction of transporter-mediated disposition remains less comprehensive, particularly for the kidney (Zamek-Gliszczynski et al., 2013; Jones et al., 2015;

ABBREVIATIONS: AUC, area under the curve; AUCR, area under the curve ratio; $\mathrm{CL}$, clearance; $\mathrm{CL}_{\mathrm{CR}}$, creatinine clearance; $\mathrm{CL} / \mathrm{F}$, oral clearance; $\mathrm{CL}_{\text {int } \mathrm{T}}$, transporter intrinsic clearance; $\mathrm{CL}_{\mathrm{PD}}$, passive diffusion clearance; $\mathrm{CL}_{\mathrm{R}}$, renal excretion clearance; $\mathrm{C}_{\text {max }} \mathrm{PT}-1$, maximum concentration in

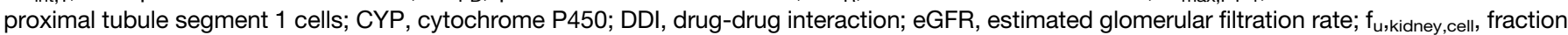
unbound in kidney cells; GFR, glomerular filtration rate; IVIVE, in vitro-in vivo extrapolation; MechKiM, mechanistic kidney model; OATP, organic anion transporting peptide; PBPK, physiologically based pharmacokinetic; P-gp, P-glycoprotein; PT, "poor transporter" phenotype; PTC, proximal tubule cells; PTCPGK, proximal tubule cells per gram kidney; REF, relative expression factor; $\mathrm{V}_{\mathrm{ss}}$, volume of distribution at steady state. 
Posada et al., 2015; Varma et al., 2015). The study of Hsu et al., (2014) investigated, through simulation, reduced proximal tubule cellularity as one possible mechanism that could cause changes in renal drug secretion in renal impairment. However, the additional plausible underlying mechanisms, namely reduced transporter expression or inhibition of transporters by uremic solutes, have not been explored. Such simulations are required to assess the implications of specific model assumptions on systemic and local drug concentrations predicted by the PBPK models. In addition, although simulations were performed to investigate changes to proximal tubule intracellular drug concentrations in a transporter mediated drug-drug interaction (DDI) scenario, such changes were not investigated in the renal impairment scenario (Hsu et al., 2014).

This study aimed to develop a PBPK kidney model for digoxin and apply the model to investigate potential effects of age and renal impairment on digoxin renal drug disposition. Rationale for selecting digoxin in this study was the large availability of clinical data to support the estimation and verification of mechanistic kidney model parameters. The initial in vitro-in vivo extrapolation (IVIVE) of digoxin renal excretion clearance $\left(\mathrm{CL}_{\mathrm{R}}\right)$ using reported in vitro OATP4C1 transporter intrinsic clearance $\left(\mathrm{CL}_{\mathrm{int}, \mathrm{T}}\right)$ resulted in under prediction of its $\mathrm{CL}_{\mathrm{R}}$. Subsequently, this parameter was estimated from collated digoxin clinical data accounting for the uncertainty in the contribution of glomerular filtration to the observed digoxin $\mathrm{CL}_{\mathrm{R}}$. The developed model was subsequently used to simulate changes in digoxin $\mathrm{CL}_{\mathrm{R}}$ due to aging and moderate and severe renal impairment. In the case of renal impairment, the impact of reduction in OATP4C1, P-gp abundance per million proximal tubule cells, or proximal tubule cellularity on digoxin $\mathrm{CL}_{\mathrm{R}}$ and its proximal tubule cell concentrations were investigated.

\section{Methods}

The overall strategy for the development and application of the PBPK kidney model for digoxin is presented as a workflow diagram in Fig. 1.

Clinical data sources. Digoxin mean plasma concentration-time profiles and pharmacokinetic parameters were collated from the scientific literature. Pharmacokinetic parameters of interest were the area under the curve (AUC) for the plasma concentration-time profile, the intravenous clearance $(\mathrm{CL})$ and oral clearance $(\mathrm{CL} / \mathrm{F})$, volume of distribution

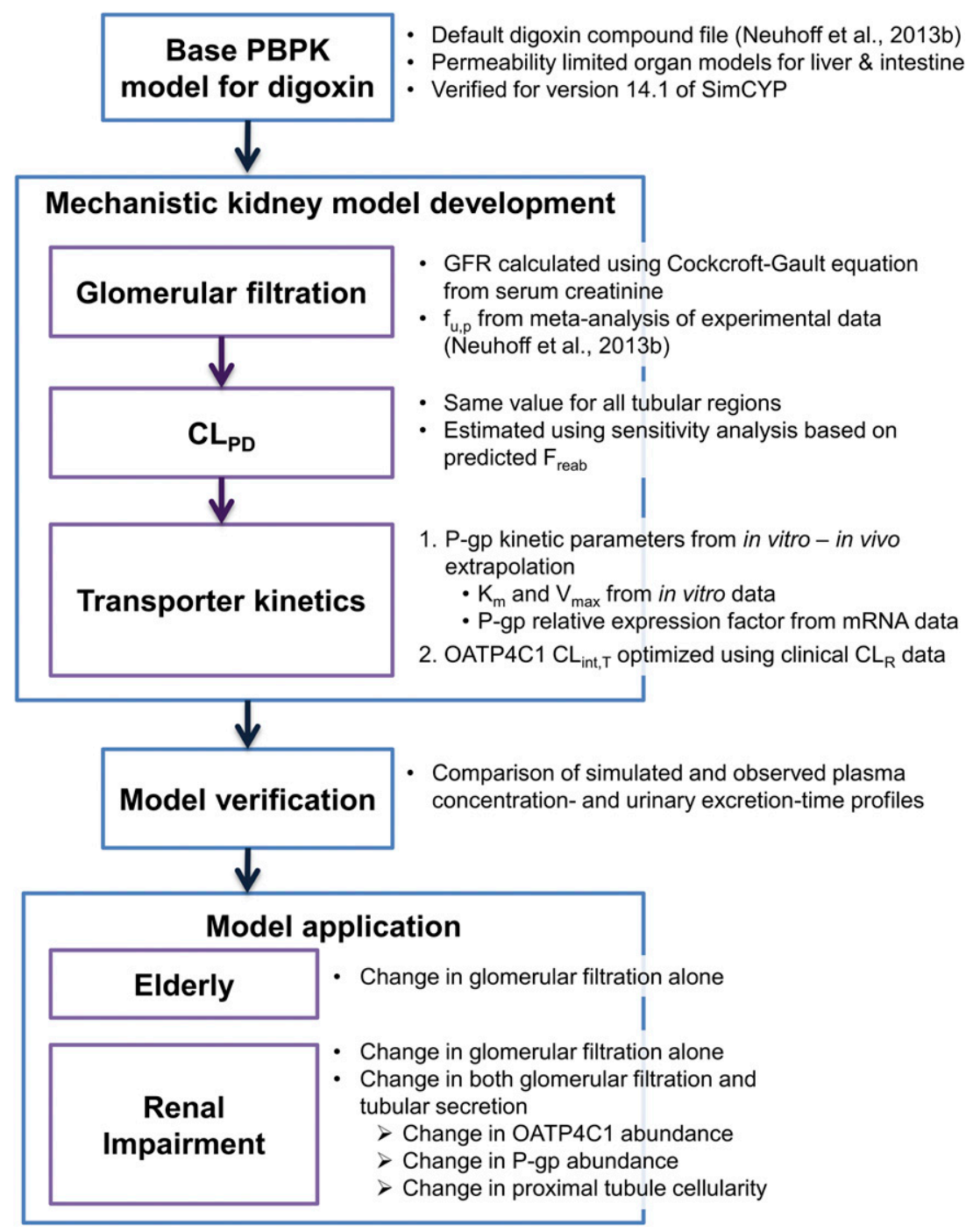

Fig. 1. Workflow of the development and application of the PBPK kidney model for digoxin. 
at steady state, and $\mathrm{CL}_{\mathrm{R}}$. Where necessary, data were digitized using GetData Digitizer (version 2, www.getdata-graph-digitizer.com).

Verification of basal PBPK model of digoxin. All simulations presented herein were performed using the SimCYP population-based PBPK simulator software, version 14, release 1 (SimCYP, Sheffield, UK) (Jamei et al., 2009; Jamei et al., 2013). Initial simulations of digoxin plasma concentration-time profiles and $C_{R}$ were performed using the default "healthy volunteers" population file provided with the SimCYP simulator. Optimized parameters for the full PBPK model of digoxin, including mechanistic models of liver and intestine, were recently published in version 12.2 of the simulator (Neuhoff et al., 2013b). The default compound file provided with version 14.1 of the SimCYP simulator (Supplemental Table S1) was verified against clinical data to ensure consistency between different versions of the software. This verification was performed using several clinical studies, with 10 trials for each set of simulations (Supplemental Table S2) using the default full-PBPK model (Neuhoff et al., 2013b). Upon visual inspection, the simulated concentration-time profiles as well as key pharmacokinetic parameters were not inconsistent with observed data (see Supplemental Fig. S1).

IVIVE of renal clearance and optimization of tubular secretion in PBPK model. Simulation of renal digoxin disposition was performed using the mechanistic kidney model (MechKiM) module in the SimCYP simulator (Neuhoff et al., 2013a). This model comprises eight segments representing the glomerulus, three subregions of proximal tubule, the loop of Henle, the distal tubule, and the cortical and medullary collecting ducts. Separate compartments represent the blood and tubular filtrate of each segment, as well as the tubular cell mass for the seven tubular segments. The model can account for glomerular filtration, passive permeability within all of the tubular segments, and active transport processes within the proximal tubule segments. Readers may refer to previous publications for model equations and assumptions (Hsu et al., 2014; Burt et al., 2016). Digoxin has low passive permeability across cell monolayers, even in the presence of P-gp inhibitors (literature Caco-2 apparent permeability range from 1.15 to $8.03 \times 10^{-6} \mathrm{~cm} / \mathrm{s}$ in various assay formats used (Neuhoff et al., 2003; Zhang and Morris, 2003; Djuv and Nilsen, 2008; Fossati et al., 2008). There are mixed reports from clinical studies suggesting possible urine flow-dependent $\mathrm{CL}_{\mathrm{R}}$ of digoxin (Steiness, 1974; Halkin et al., 1975; Steiness et al., 1982) and potential role of passive tubular reabsorption in vivo (although minor). Although prediction of tubular reabsorption clearance from physicochemical properties was recently reported, the validated quantitative structurepharmacokinetic property relationship model does not allow for prediction of passive diffusion clearance $\left(\mathrm{CL}_{\mathrm{PD}}\right)$ values in different regions of the nephron (Dave and Morris, 2015). Recently, a static model for prediction of tubular reabsorption was reported that considered regional differences in physiologic parameters for prediction of fraction reabsorbed; this model has not been validated in the MechKiM using appropriate range of model compounds (Scotcher et al., 2016c). To account for tubular reabsorption in the current model, the same value for $\mathrm{CL}_{\mathrm{PD}}$ parameter $(0.01 \mu \mathrm{l} / \mathrm{min} / \mathrm{million}$ tubule cells $)$ was assigned to all tubular compartments (i.e., proximal tubule, loop of Henle, distal tubule, and collecting duct). This assigned value for $\mathrm{CL}_{\mathrm{PD}}$ resulted in simulated fraction reabsorbed for digoxin of 0.12 , in agreement with the range predicted using the static model of tubular reabsorption using the Caco-2 apparent permeability literature permeability data (predicted range using static model $=0.064-0.34$; see Supplemental Fig. S2) (Scotcher et al., 2016c). The assumption of equal $C_{\mathrm{PD}}$ for each tubular region may underestimate the $\mathrm{CL}_{\mathrm{PD}}$ in proximal tubule, because its surface area is greater than for the other tubular regions (Scotcher et al., 2016c). Such underestimation of $\mathrm{CL}_{\mathrm{PD}}$ in proximal tubule could subsequently lead to underestimation of OATP4C1 $\mathrm{CL}_{\text {int,T. }}$. Fraction unbound in kidney cells ( $\left.f_{u, k i d n e y, c e l l}\right)$ of 0.51 was predicted using the Rodgers and Rowland method (Rodgers et al., 2005; Rodgers and Rowland, 2006).

Digoxin secretion in kidney is considered to be mediated predominantly by the OATP4C1 and P-gp transporters, expressed on the basolateral and apical proximal tubule membranes, respectively (Tanigawara et al., 1992; Mikkaichi et al., 2004; He et al., 2014; Lee et al., 2014). A wide range of in vitro $K_{\mathrm{m}}$ and $V_{\max }$ values were available for P-gp in the literature, with two studies reporting in vitro data for OATP4C1 (Supplemental Table S3). For consistency, the P-gp $K_{\mathrm{m}}(\mu \mathrm{M})$ and $V_{\max }$ (pmol/min/million cells) parameter values in the mechanistic kidney model were the same as those implemented in the pre-existing mechanistic models for liver and intestine (Troutman and Thakker, 2003; Neuhoff et al., 2013b). For the transporters, sensitivity analyses were performed by modifying the OATP4C1 $\mathrm{CL}_{\mathrm{int}, \mathrm{T}}$ and/or the $\mathrm{P}$-gp relative expression factor (REF) parameters.

P-gp mRNA expression data in kidney and Caco-2 cells were used to inform the REF parameter for this transporter. This inherently assumes that mRNA expression at the tissue level is representative of expression at the cellular level. Lack of quantitative information on differences in P-gp protein expression and activity between different tissues at the cellular level precluded a more mechanistic approach. Because of the lack of in vitro $V_{\max }$ values reported in the literature, OATP4C1 $\mathrm{CL}_{\text {int,T }}$ was estimated from reported uptake rate $(\mathrm{dX} / \mathrm{dt})$ and initial substrate concentration (C) data (Mikkaichi et al., 2004; Chu et al., 2007), using eq. 1 , which assumes that $\mathrm{C}<<K_{\mathrm{m}}$.

$$
C L_{\text {int }, T}=\frac{d X / d t}{C}
$$

As the transporter expression/abundance data needed to inform the $\mathrm{REF}$ scaling factor were lacking, in vitro OATP4C1 $\mathrm{CL}_{\text {int,T }}$ was normalized to proximal tubule cellularity (Supplemental Table S3), as previously attempted for OCT2 uptake activity (Li et al., 2014). Normalization was performed by assuming equal expression/activity of OATP4C1 in transfected cells and proximal tubule cells and a cellularity of 13 million Madin-Darby canine kidney cells per milligram protein (Richardson et al., 1981). Although large uncertainty is associated with the number of proximal tubule cells per gram of kidney (PTCPGK) in human (Scotcher et al., 2016b), a value of 60 million cells/g kidney was used for this model parameter, in accordance with previous simulation studies (Neuhoff et al., 2013a; Hsu et al., 2014; Li et al., 2014).

As the IVIVE approach outlined above did not successfully predict clinically observed digoxin $\mathrm{CL}_{\mathrm{R}}$, OATP4C1 $\mathrm{CL}_{\mathrm{int}, \mathrm{T}}$ was estimated using collated digoxin clinical data. First, parameter estimation was performed by fitting the model to the observed plasma concentration profiles of 9 clinical studies after intravenous administration (Johnson and Bye, 1975; Koup et al., 1975; Ochs et al., 1978; Kramer et al., 1979; Ding et al., 2004), using the automated parameter estimation module of the SimCYP simulator. As simultaneous fitting of all data were not possible in the SimCYP software, fitting was performed using each dataset separately, and the overall weighted (by subject number) mean estimate of OATP4C1 $\mathrm{CL}_{\mathrm{int}, \mathrm{T}}$ was subsequently calculated. In addition, the observed overall weighted (by subject number) mean $\mathrm{CL}_{\mathrm{R}}$ collated from 19 clinical studies in total (Supplemental Table S4) was used to optimize OATP4C1 $\mathrm{CL}_{\text {int,T }}$ using a detailed sensitivity analysis. In this approach, digoxin pharmacokinetics was simulated using various values of OATP4C1 $\mathrm{CL}_{\mathrm{int}, \mathrm{T}}$ and serum creatinine in a population representative. The OATP4C1 $\mathrm{CL}_{\text {int,T }}$ that resulted in the simulated $\mathrm{CL}_{R}$ in closest agreement with the observed data when serum creatinine was fixed to $80 \mu \mathrm{mol} / /$ (corresponding to glomerular filtration rate of $120 \mathrm{ml} / \mathrm{min}$ in the population representative) was taken forward as the optimal value. This optimization procedure was performed using two separate clinical study designs that had different doses and some differences in the age range. Significant dose-related differences were not expected, because OATP4C1 $\mathrm{CL}_{\mathrm{int}, \mathrm{T}}$ is assumed to be within the linear range of kinetics (Kramer et al., 1979; Rengelshausen et al., 2003). The final model was verified against plasma and urinary digoxin concentration data from additional clinical studies that were not included in the model development (Johnson and Bye, 1975; Ochs et al., 1978; Lindenbaum et al., 1981). In addition, simulation of digoxin plasma concentration data using the final mechanistic model was compared with digoxin PBPK model where mechanistic kidney model was not included and $\mathrm{CL}_{\mathrm{R}}$ was defined as a single input parameter. 
Simulation of digoxin $\mathrm{CL}_{\mathbf{R}}$ in elderly and renal impairment populations. Digoxin pharmacokinetics was simulated in 100 virtual subjects after intravenous infusion (30 minutes) of $0.75 \mathrm{mg}$ in different virtual populations, with other trial design parameters such as age range and proportion of women of the virtual subjects determined by the general values of the relevant population files. The virtual populations used for simulations included the "Geriatric NEC", "RenalGFR_30-60", and "RenalGFR_less_30" populations, which were supplied with the SimCYP simulator. Geriatric NEC population accounts for changes in the age-sex distribution, weights, and heights and kidney size of subjects, whereas the RenalGFR_ populations account for changes in glomerular filtration rate (GFR), protein binding by albumin, hematocrit, kidney weight, and renal blood flow in different stages of renal impairment. There are conflicting reports that digoxin volume of distribution may be altered in patients with end-stage renal disease (Jusko and Weintraub, 1974; Cheng et al., 1997); because of the lack of concordant results on the magnitude of such changes and the fact that these patients were not simulated here, this aspect was not captured in the current study.

In addition the "RenalGFR_30-60" and "RenalGFR_less_30" populations were modified by reducing the value of the PTCPGK parameter. Reducing PTCPGK in the model was investigated as a way to mechanistically represent changes in secretion resulting from tubular cell damage, which may occur during renal impairment and injury (and possibly aging) (Nangaku, 2006; Andreucci et al., 2014; Wang et al., 2014). Alternatively, change in expression of drug transporters per million proximal tubule cells was explored as a mechanism contributing to reduced renal secretion, in line with limited biological data (Naud et al., 2011; Wang and Sweet, 2013). Changes to abundance of the OATP4C1 (basolateral membrane) or P-gp transporters (apical membrane) or PTCPGK were each simulated separately. Although changing the PTCPGK parameter or transporter abundance per million proximal tubule cells for a specific transporter will have the same net effect on overall transporter abundance for that specific transporter per individual (after scaling for kidney weight of the individual), some important differences should be noted. Changes in proximal tubule cell number (i.e., PTCPGK) will affect the overall abundance per kidney of all transporters, as well as scaled CLPD per kidney. The latter will not occur when the transporter abundance per million proximal tubule cells is changed. In addition, the MechKiM model uses the PTCPGK parameter to define the cellularity of all tubular regions, including loop of Henle, distal tubule, and collecting duct compartments. Thus changing the PTCPGK can affect the scaled CLPD $_{\text {in the distal tubular }}$ regions and therefore the tubular reabsorption, a factor that is not directly affected by changes to transporter abundance parameters. Reduced abundance of kidney drug transporters per million proximal tubule cells was represented in MechKiM by assigning relative abundances for the OATP4C1 and P-gp transporters in kidney in the "poor transporter" (PT) phenotype as a proportion the SimCYP default "extensive transporter" phenotype value of 1 and setting the frequency of $\mathrm{PT}$ in the modified population to 1 . Separate changes to PTCPGK or transporter abundance parameters applied equally to each of the three subregion of the proximal tubule. Relative abundance of P-gp in liver and gut remained the same. AUC ratio (AUCR) was calculated using eq. 2 :

$$
A U C R=\frac{A U C_{R I}}{A U C_{\text {Control }}}
$$

where $\mathrm{AUC}_{\mathrm{RI}}$ and $\mathrm{AUC}_{\mathrm{Control}}$ are the mean digoxin $\mathrm{AUC}$ in renal impairment subjects $\left(\mathrm{GFR}<60 \mathrm{ml} / \mathrm{min} / 1.73^{2}\right)$ and mean digoxin AUC in healthy volunteers or patients without renal impairment (GFR > $\left.60 \mathrm{ml} / \mathrm{min} / 1.73^{2}\right) . \mathrm{CL}_{\mathrm{R}}$ ratio and maximum concentration of digoxin in the cells of the first of the three proximal tubule segments $\left(\mathrm{C}_{\text {max,PT-1 }}\right)$ ratio were calculated in an analogous manner.

Separately, simulations were performed in the population representative mode after changes in systems parameters in the kidney model, using the "healthy volunteers" population file as a template. In these simulations, digoxin $\mathrm{CL}_{\mathrm{R}}$ was simulated after changes in GFR either alone or in combination with proportional changes in the OATP4C1 abundance per million proximal tubule cells or PTCPGK parameter (see Table 1 for details).

\section{Results}

Optimization of digoxin kidney transporter kinetic parameters. The relevance of individual renal mechanisms for digoxin $\mathrm{CL}_{\mathrm{R}}$ was assessed using the MechKiM module in a stepwise manner. Consideration of either glomerular filtration in isolation or both glomerular filtration and passive tubular reabsorption resulted in simulated digoxin $\mathrm{CL}_{\mathrm{R}}$ of 98.8 or $87.3 \mathrm{ml} / \mathrm{min}$, respectively, which were both lower than the overall weighted (by subject number) mean observed value of $136.1 \mathrm{ml} / \mathrm{min}$ (Supplemental Table S4). Digoxin plasma concentration time profiles for these scenarios are presented in Fig. 2. Simulated $\mathrm{AUC}_{0-\infty}$ was $29 \%$ and $39 \%$ higher compared with setting when MechKiM was not activated (i.e., $\mathrm{CL}_{\mathrm{R}}$ defined using single input parameter) for the "filtration only" and "filtration and reabsorption" scenarios, respectively.

The sensitivity of simulated digoxin $\mathrm{CL}_{\mathrm{R}}$ and AUC to model input parameters was assessed to determine their relative

TABLE 1

Parameters used to simulate digoxin $\mathrm{CL}_{\mathrm{R}}$

Reduction in filtration and secretion was performed to represent changes in renal impairment. Simulated population representative of the "healthy volunteers" population had an age, weight, and body surface area of 20 years, $81 \mathrm{~kg}$, and $1.98 \mathrm{~m}^{2}$, respectively. Serum creatinine (input parameter of model) was calculated for each scenario using the CockcroftGault equation (Cockcroft and Gault, 1976), based on the target GFR and the age, weight, and body surface area of the population representative.

\begin{tabular}{lccc}
\hline \multicolumn{1}{c}{ GFR } & Serum Creatinine Concentration & OATP4C1 Abundance & PTCPGK \\
\hline $\mathrm{ml} / \mathrm{min} / 1.73 \mathrm{~m}^{2}$ & $\mu$ mol $/ l$ & & million PTC/g kidney \\
$136.4^{a}$ & 76.5 & 1 & 60 \\
140 & 74.5 & 1.03 & 61.6 \\
120 & 86.9 & 0.88 & 52.8 \\
100 & 104.3 & 0.73 & 44.0 \\
80 & 130.4 & 0.59 & 35.2 \\
60 & 173.9 & 0.44 & 26.4 \\
40 & 260.8 & 0.29 & 17.6 \\
20 & 521.7 & 0.15 & 8.8 \\
15 & 695.6 & 0.11 & 6.6 \\
\hline
\end{tabular}

${ }^{a}$ Relative change in GFR for each scenario was calculated using the value of $136.4 \mathrm{ml} / \mathrm{min} / \mathrm{m}^{2}$ as baseline and applied to the OATP4C1 abundance or PTCPGK parameter. 


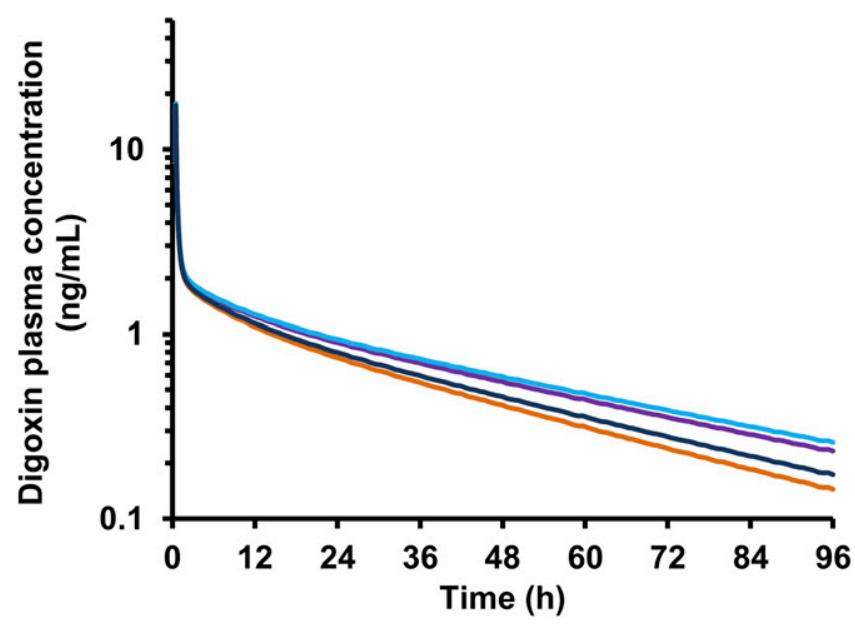

Fig. 2. Mean simulated digoxin plasma concentration time profiles (intravenous administration of $1 \mathrm{mg}$ digoxin) for intermediate PBPK models used during development of the mechanistic kidney model. $\mathrm{CL}_{\mathrm{R}}$ defined by a single input value $(136.1 \mathrm{ml} / \mathrm{min})$ based on the literature analysis (orange line) and $\mathrm{CL}_{\mathrm{R}}$ simulated using the mechanistic kidney model, accounting for only glomerular filtration (purple line), glomerular filtration and reabsorption (turquoise line), or glomerular filtration, reabsorption, and active secretion (blue line).

importance. Simulated digoxin $\mathrm{CL}_{\mathrm{R}}$ and systemic exposure were highly sensitive to changes in OATP $4 \mathrm{C} 1 \mathrm{CL}_{\text {int, } \mathrm{T}}$, in contrast to the marginal effect of changes in P-gp REF (Fig. 3A). Simulated $\mathrm{C}_{\max }$ PT-1 was sensitive to changes in both OATP4C1 $\mathrm{CL}_{\text {int,T }}$ and P-gp REF (Fig. 3B). The simulated digoxin $\mathrm{CL}_{\mathrm{R}}$ and $\mathrm{AUC}_{0-\infty}$ were insensitive to changes in $f_{u, k i d n e y, c e l l}$, with minor changes noted at $f_{u, k i d n e y, c e l l}<0.2$ (Supplemental Fig. S3, A and B). $\mathrm{C}_{\max }, \mathrm{PT}-1$ was sensitive to changes in $\mathrm{f}_{\mathrm{u} \text {,kidney,cell }}$ at values below approx. 0.4 (Supplemental Fig. S3C).

Three studies reported P-gp relative mRNA expression between kidney and intestine (Supplemental Table S5). Multiplying these values by the intestine: Caco-2 REF of 2.04 used in the SimCYP gut module resulted in kidney: Caco-2 REFs ranging from 0.78 to 5.34. However, the cellular and tissue expression data were reported in different studies. Therefore, the P-gp REF for Caco-2 cells: kidney used in the final digoxin kidney model (1.51) was based on P-gp mRNA expression data reported in both systems in the same study (Hilgendorf et al., 2007). In vitro OATP4C1-mediated uptake clearance of digoxin was calculated from two uptake rate values reported in the literature (Table 2 ). In vitro uptake clearance values varied by $\sim 3$ orders of magnitude, and the use of these values to inform the OATP4C1 $\mathrm{CL}_{\text {int, } \mathrm{T}}$ parameter (i.e., IVIVE) resulted in over eightfold difference in simulated $\mathrm{CL}_{\mathrm{R}}$ (Table 2), representing $67 \%$ and $591 \%$ of the observed value (Supplemental Table S4).

Alternatively, OATP4C1 $\mathrm{CL}_{\text {int,T }}$ was obtained by parameter estimation by fitting the model to the observed plasma concentration-time profiles after intravenous administration. Fitting the model separately to the plasma concentration-time profiles from nine clinical studies resulted in weighted mean OATP4C1 $\mathrm{CL}_{\text {int,T }}$ of $1.85 \mu \mathrm{l} / \mathrm{min} / \mathrm{million}$ PTC (Table 2). By using this weighted mean OATP4C1 $\mathrm{CL}_{\text {int,T }}$ value, simulated digoxin $\mathrm{CL}_{\mathrm{R}}$ was $80 \%$ of the observed value. A sensitivity analysis based approach was next used for estimation of the OATP4C1 $\mathrm{CL}_{\text {int,T }}$ parameter. The overall weighted mean observed $\mathrm{CL}_{\mathrm{R}}$ of digoxin obtained from extensive literature search $(136.1 \mathrm{ml} / \mathrm{min} ; n=214$ healthy subjects $)$ was used as the optimal value (Supplemental Table S4). By using a population representative, digoxin pharmacokinetics were simulated using different OATP4C1 $\mathrm{CL}_{\text {int,T }}$ and serum creatinine input parameter values. The estimated OATP4C1 $\mathrm{CL}_{\text {int,T }}$ value, based on the sensitivity analysis approach using a fixed serum creatinine value of $80 \mu \mathrm{mol} / \mathrm{l}$, was $4.14 \mu \mathrm{l} / \mathrm{min} / \mathrm{million}$ PTC (Fig. 4). A serum creatinine value of $80 \mu \mathrm{mol} / \mathrm{l}$ was an assumed average value, because 12 of 19 of the clinical studies used in the literature analysis did not report serum creatinine, creatinine clearance $\left(\mathrm{CL}_{\mathrm{CR}}\right)$, or other measurements/estimates of GFR of subjects enrolled. The comparison of simulated (colored mesh) and observed (gray plane) digoxin $\mathrm{CL}_{\mathrm{R}}$ in Fig. 4 indicates a range of possible values for optimized OATP4C1 $\mathrm{CL}_{\text {int,T }}$ (i.e., various intersections between simulated and observed $\mathrm{CL}_{\mathrm{R}}$ ), depending on the assumed serum creatinine value. From the mean GFR or $\mathrm{CL}_{\mathrm{CR}}$ data in the 7 digoxin clinical studies that reported these values, the minimum and maximum serum creatinine concentrations (54 and $108 \mu \mathrm{M}$ ) were calculated. Estimation of the OATP4C1 $\mathrm{CL}_{\text {int,T }}$ parameter assuming these values resulted in twofold differences in the optimized value, as illustrated by Fig. 4 . Based on this sensitivity analysis, the estimated OATP4C1 CL $\mathrm{C}_{\text {int,T }}$ value would reliably support conclusions drawn from extrapolation within the context of the current study. All digoxin MechKiM parameters in the developed model are listed in Table 3.

After optimization of the OATP4C1 $\mathrm{CL}_{\text {int,T }}$ parameter, digoxin pharmacokinetics were then simulated after clinical trial designs reported in studies (Johnson and Bye, 1975; Ochs et al., 1978; Lindenbaum et al., 1981) that were not used in the model development/optimization. Simulated plasma concentration and urinary excretion rate profiles were not inconsistent with the observed data (Fig. 5). In addition, simulated digoxin plasma concentrations were comparable before and after activation of MechKiM to define the $\mathrm{CL}_{\mathrm{R}}$ of digoxin (Fig. 2).

Simulation of digoxin pharmacokinetics in special populations: effects of age and renal impairment. Mean digoxin $\mathrm{CL}_{\mathrm{R}}$ simulated in elderly virtual subjects ("Sim-Geriatric NEC" population file) was $90.7 \mathrm{ml} / \mathrm{min}, 31 \%$ lower than simulated $\mathrm{CL}_{\mathrm{R}}$ in for healthy volunteers (Table 4). This change in digoxin $\mathrm{CL}_{\mathrm{R}}$ was comparable to the relative change observed in clinical study [36\% lower $\mathrm{CL}_{\mathrm{R}}$ in elderly subjects relative to young subjects (Ewy et al., 1969)], but lower than the relative change in simulated GFR [44\% lower in elderly, compared with 54\% observed (Ewy et al., 1969)].

Mean predicted digoxin $\mathrm{CL}_{\mathrm{R}}$ in moderate (GFR_30-60) and severe (GFR_less_30) renal impairment virtual populations were $50 \%$ and $67 \%$ lower than in the simulated healthy volunteers (Table 4). The mean GFR of the virtual subjects with moderate and severe renal impairment were $64 \%$ and $82 \%$ lower than in the simulated healthy volunteers. Comparison of the observed clinical data with predicted $\mathrm{CL}_{\mathrm{R}}$ and GFR in the healthy, moderate renal impairment and severe renal impairment virtual populations are shown in Fig. 6A. Although some agreement between predicted and observed data were noted, there was a general trend of overestimation of $\mathrm{CL}_{\mathrm{R}}$ in the renal impairment populations. The extent of overestimation of $\mathrm{CL}_{\mathrm{R}}$ was directly correlated with high expression of OATP4C1 in virtual subjects. Average predicted AUCR in moderate renal impairment (1.4) was in agreement with clinical data (1.3). In contrast, model predicted changes in digoxin systemic exposure in severe renal impairment (predicted AUCR of 1.5) were significantly underestimated in comparison with clinical data $(\mathrm{AUCR}=3.3$ ) (Okada et al., 

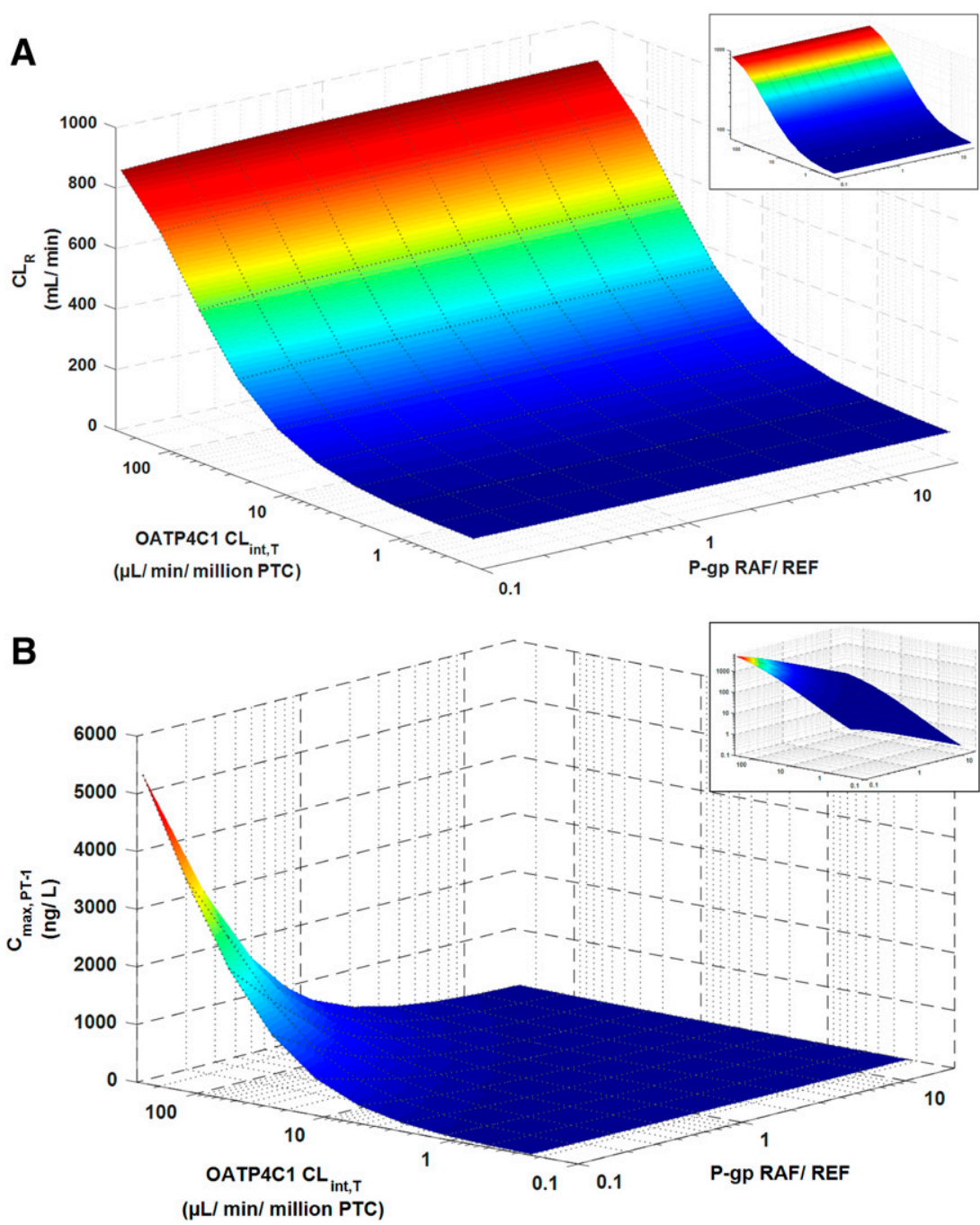

Fig. 3. Simulated digoxin $\mathrm{CL}_{\mathrm{R}}(\mathrm{A})$ and $\mathrm{C}_{\max }$ PT-1 $(\mathrm{B})$ at different input values for the kidney transporter kinetic parameters. Values of OATP4C1 $\mathrm{CL}_{\text {int, } \mathrm{T}}$ and P-gp REF were varied using the automated sensitivity analysis tool in the SimCYP simulator in a population representative following the clinical trial design reported previously (Greiner et al., 1999). Insets show the graphs presented on logarithmic scales.
1978). GFR and OATP4C1 relative abundance per million proximal tubule cells had similar coefficient of determination $\left(R^{2}\right)$ of the line of best fit with simulated $\mathrm{CL}_{\mathrm{R}}$ in healthy virtual subjects (Fig. 6B). In contrast, a stronger correlation between either OATP4C1 relative abundance or PTCPGK and $\mathrm{CL}_{\mathrm{R}}$ was noted in virtual subjects with renal impairment compared with healthy (data not shown).

Reduction in OATP4C1 relative abundance per million proximal tubule cells in the renal impairment virtual populations (decrease in REF from 1 to 0.125 ) or scenario with comparable changes in proximal tubule cell number (7.5-60 million proximal tubule cells/g kidney) both resulted in similar predicted impact on digoxin $\mathrm{CL}_{\mathrm{R}}$ and AUCR (Fig. 7). For example, maximal reduction in PTCPGK or OATP4C1 abundance per million proximal tubule cells simulated in the severe renal impairment population resulted in predicted $\mathrm{CL}_{\mathrm{R}}$ ratios of 0.164 or 0.152 , respectively (Fig. 7). In contrast to systemic exposure, model assumptions used showed differential effect in the predicted digoxin concentration in the proximal tubule. Reduced PTCPGK had minimal impact on simulated digoxin concentrations in proximal tubule cells, whereas reduced OATP4C1 or P-gp abundance per million proximal tubule cells decreased or increased digoxin intra-cellular concentrations, respectively (Fig. 7).
Equal $\mathrm{CL}_{\mathrm{PD}}$ was assigned for each tubular region, which may underestimate the $\mathrm{CL}_{\mathrm{PD}}$ in proximal tubule because of its larger surface area. However, the impact was marginal in the case of digoxin, considering low $\mathrm{CL}_{\mathrm{PD}}$ in proximal tubule compartment relative to transporter kinetic parameters. Simulations performed to assess the potential impact of underestimation of $\mathrm{CL}_{\mathrm{PD}}$ in proximal tubule demonstrated that increase in this parameter up to fivefold would have minor overall impact on digoxin $\mathrm{CL}_{\mathrm{R}}$ and $\mathrm{C}_{\text {max,PT-1 }}$ ratios (Supplemental Fig. S4).

Further simulations were performed in population representative mode, using the "healthy volunteers" population as a template, whereby GFR was altered either alone or alongside proportionally altered OATP4C1 abundance or PTCPGK (Fig. 8). Accounting for changes in tubular secretion in renal impairment, assuming that either OATP4C1 abundance per million proximal tubule cells or PTCPGK are affected proportionally to changes in GFR, resulted in improved agreement between simulated and observed digoxin $\mathrm{CL}_{\mathrm{R}}$ (Fig. 8).

\section{Discussion}

Use of PBPK kidney models is challenged by a lack of physiological data to inform system parameters and scaling 
TABLE 2

Values of the OATP4C1 CL $\mathrm{C}_{\text {int,T }}$ parameter estimated by various methods and subsequent simulated digoxin CLR in healthy volunteers using the intravenous trial design from Greiner et al. (1999)

\begin{tabular}{|c|c|c|}
\hline Source of Data & OATP4C1 $\mathrm{CL}_{\text {int,T }}$ Value & Simulated Digoxin $\mathrm{CL}_{\mathrm{R}}$ \\
\hline & $\mu \mathrm{l} / \mathrm{min} /$ million PTC & $\mathrm{ml} / \mathrm{min}$ \\
\hline \multicolumn{3}{|l|}{ In vitro-in vivo extrapolation } \\
\hline MDCK-OATP4C1 (Mikkaichi et al., 2004) & 0.23 & 90.6 \\
\hline CHO-OATP4C1 (Chu et al., 2007) & 270 & 804.3 \\
\hline \multicolumn{3}{|l|}{ Parameter estimation: Fitting to plasma concentration-time profile } \\
\hline $1 \mathrm{mg}$, i.v. bolus ( $n=12$ subjects) (Kramer et al., 1979) & 8.20 & \\
\hline $\begin{array}{l}0.01 \mathrm{mg} / \mathrm{kg} \text {, i.v. } 4 \mathrm{~min} \text { infusion ( } n=12 \text { subjects) (Rengelshausen } \\
\text { et al., 2003) }\end{array}$ & 1.10 & \\
\hline $0.5 \mathrm{mg}$, i.v. $5 \mathrm{~min}$ infusion ( $n=12$ subjects) (Ding et al., 2004) & 0 & \\
\hline 0.75 mg, i.v. bolus ( $n=8$ subjects) (Koup et al., 1975) & 0.09 & \\
\hline $0.75 \mathrm{mg}$, i.v. $1 \mathrm{~h}$ infusion ( $n=8$ subjects) (Koup et al., 1975) & 5.56 & \\
\hline $0.75 \mathrm{mg}$, i.v. 3 min infusion ( $n=8$ subjects) (Johnson and Bye, 1975) & 3.30 & \\
\hline $0.5 \mathrm{mg}$, i.v. $1 \mathrm{~h}$ infusion ( $n=9$ subjects) (Ochs et al., 1978$)$ & 0 & \\
\hline $1 \mathrm{mg}$, i.v. $1 \mathrm{~h}$ infusion ( $n=9$ subjects) (Ochs et al., 1978$)$ & 0 & \\
\hline $1.5 \mathrm{mg}$, i.v. $1 \mathrm{~h}$ infusion ( $n=9$ subjects) (Ochs et al., 1978) & 0 & \\
\hline Overall weighted mean \pm standard deviation & $1.85 \pm 2.87$ & 108.8 \\
\hline \multicolumn{3}{|l|}{ Parameter estimation: Sensitivity analysis } \\
\hline $\begin{array}{l}\text { Overall weighted mean } \mathrm{CL}_{\mathrm{R}}{ }^{a} \text { (Population representative using trial } \\
\text { design } 1 \mathrm{mg} \text {, i.v. bolus (Kramer et al., 1979)) }\end{array}$ & 4.14 & 133.4 \\
\hline $\begin{array}{l}\text { Overall weighted mean } \mathrm{CL}_{\mathrm{R}}{ }^{a} \text { (Population representative using trial } \\
\text { design } 0.01 \mathrm{mg} / \mathrm{kg} \text {, i.v. } 4 \mathrm{~min} \text { infusion (Rengelshausen et al., 2003)) }\end{array}$ & 4.14 & 133.4 \\
\hline
\end{tabular}

PTC, proximal tubule cells; MDCK, Madin-Darby canine kidney.

${ }^{a} \mathrm{CL}_{\mathrm{R}}$ data presented in Supplemental Table S4.

factors, the need for various in vitro data, and availability of suitable clinical data for the drug and population(s) of interest (Scotcher et al., 2016a,b). In an attempt to overcome such challenges in the current study, digoxin was selected as a model drug because of availability of in vitro data and ample clinical data (both plasma and urine) measured in healthy subjects and special populations (e.g., elderly and renal impairment).

Modeling challenges highlighted above are more substantial when considering effects of renal pathophysiology on tubular drug secretion, because the exact contribution of different underlying mechanisms is not fully known. A previous study simulated the impact of reduced proximal tubule cellularity on plasma drug concentrations and $\mathrm{CL}_{\mathrm{R}}(\mathrm{Hsu}$ et al.,
2014). However, experimental data on proximal tubule cellularity for healthy and diseased kidneys are unlikely to become available soon, whereas information on inhibitory potential of uremic solutes on renal transporters and transporter abundances are now emerging (Fallon et al., 2016; Hsueh et al., 2016; Prasad et al., 2016). In the current study, after evaluation in the healthy population, a PBPK kidney model for digoxin was applied to investigate the simulated effect of renal impairment on plasma concentrations, $\mathrm{CL}_{\mathrm{R}}$ and proximal tubule concentrations. Modifications made to different physiological parameters of the model, designed to mimic different underlying mechanisms affecting renal secretion, had divergent effects on output parameters.

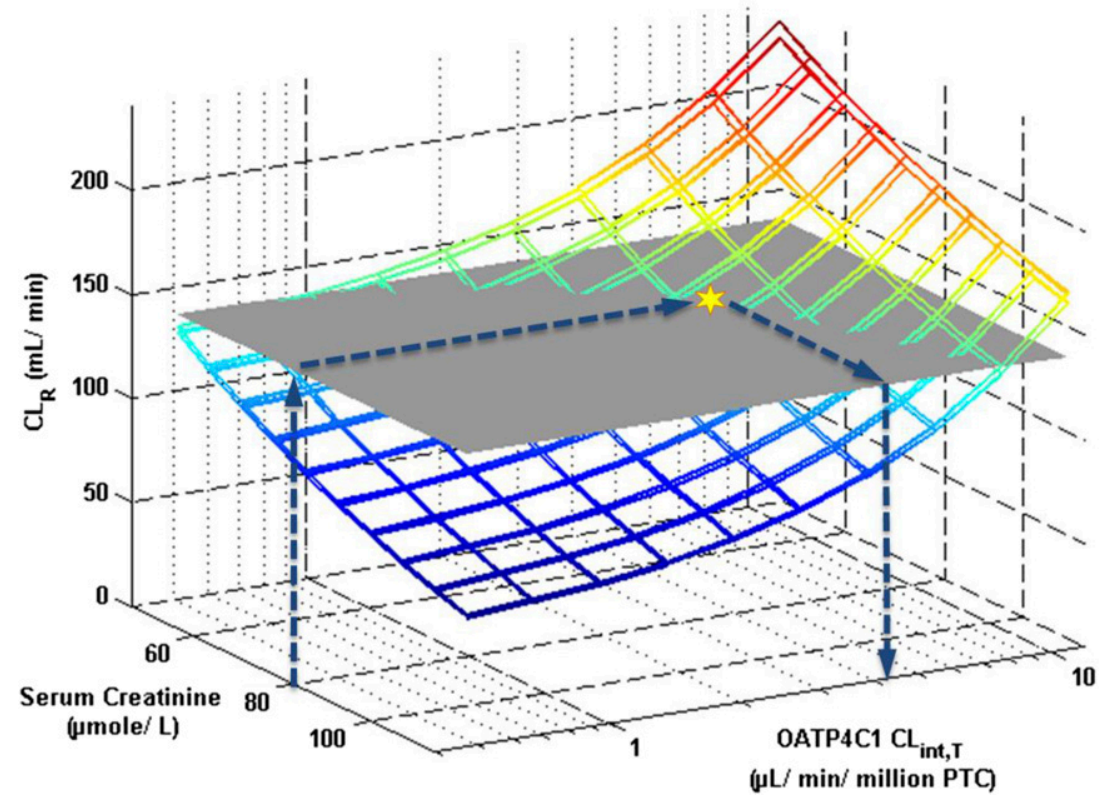

Fig. 4. Estimation of OATP4C1 $\mathrm{CL}_{\mathrm{int}, \mathrm{T}}$ parameter using a sensitivity analysis approach by simulating digoxin $\mathrm{CL}_{\mathrm{R}}$ in population representatives with different serum creatinine values. Colored meshes and gray horizontal plane indicate the simulated $\mathrm{CL}_{\mathrm{R}}$ and the overall weighted (by subject number) mean $\mathrm{CL}_{\mathrm{R}}$ obtained from the literature analysis $(136.1 \mathrm{ml} / \mathrm{min} ; n=214$ healthy subjects), respectively. Values of OATP $4 \mathrm{C} 1 \mathrm{CL}_{\mathrm{int}, \mathrm{T}}$ and serum creatinine parameters were varied using the automated sensitivity analysis tool in the SimCYP simulator. Optimal OATP4C1 value was taken at the intersection (yellow star) of the simulated digoxin $\mathrm{CL}_{\mathrm{R}}$ with the observed $\mathrm{CL}_{\mathrm{R}}$ at a serum creatinine value of $80 \mu \mathrm{mol} / \mathrm{l}$ (which corresponds to simulated GFR $\sim 120 \mathrm{ml} / \mathrm{min}$ ), as indicated by the blue arrows. Sensitivity analysis was performed twice using clinical trial designs reported previously (Kramer et al., 1979; Rengelshausen et al., 2003). 
TABLE 3

MechKiM parameter values for digoxin model

\begin{tabular}{|c|c|c|}
\hline Description (units) & Value & Comment \\
\hline $\begin{array}{l}f_{u, \text { kidney }} \\
f_{u, \text { urine }}\end{array}$ & $\begin{array}{l}0.51 \\
1\end{array}$ & Predicted (Rodgers et al., 2005; Rodgers and Rowland, 2006) \\
\hline OATP4C1 CL $\mathrm{L}_{\text {int, } \mathrm{T}}(\mu \mathrm{l} / \mathrm{min} / \mathrm{million} \mathrm{PTC})$ & 4.14 & $\begin{array}{l}\text { Estimated using sensitivity analysis Allocated to OAT1/ SLC22A6 } \\
\text { transporter in MechKiM as OATP4C1 not defined in model }\end{array}$ \\
\hline OATP4C1 RAF/ REF & 1 & \\
\hline P-gp $K_{\mathrm{m}}(\mu \mathrm{M})$ & 177 & Same as liver/gut (Neuhoff et al., 2013b) \\
\hline P-gp $V_{\max }(\mathrm{pmol} / \mathrm{min} /$ million PTC $)$ & 434 & Same as liver/gut (Neuhoff et al., 2013b) \\
\hline P-gp REF & 1.51 & Calculated from mRNA expression data (Hilgendorf et al., 2007) \\
\hline $\mathrm{CL}_{\mathrm{PD}}(\mu \mathrm{l} / \mathrm{min} / \mathrm{million} \mathrm{PTC})$ & 0.01 & $\begin{array}{l}\text { Estimated using sensitivity analysis and comparing simulated } F_{\text {reab }} \\
\text { with that predicted using static tubular reabsorption model (Scotcher } \\
\text { et al., 2016c) and published Caco-2 data (Neuhoff et al., 2003; Zhang } \\
\text { and Morris, 2003; Djuv and Nilsen, 2008; Fossati et al., 2008). Same } \\
\text { value for apical and basolateral membranes in all segments of } \\
\text { nephron }\end{array}$ \\
\hline
\end{tabular}

$\mathrm{f}_{\mathrm{u}, \text { kidney }}$, fraction unbound in kidney; $\mathrm{f}_{\mathrm{u} \text {,urine, }}$, fraction unbound in urine; $\mathrm{F}_{\text {reab }}$, fraction reabsorbed; $\mathrm{CL}_{\mathrm{int}, \mathrm{T}}$, transporter intrinsic clearance; $\mathrm{CL}_{\mathrm{PD}}$ permeability diffusion clearance; $K_{\mathrm{m}}$, Michaelis constant; MechKiM, mechanistic kidney model in SimCYP simulator; PTC, proximal tubule cells; $\mathrm{RAF}$, relative activity factor; $\mathrm{REF}$, relative activity factor; $V_{\max }$, maximal velocity.

Development of mechanistic kidney model for digoxin. A PBPK model for digoxin was previously published and incorporated permeability-limited organ models for the gut and liver (Neuhoff et al., 2013b,c). In the current study the mechanistic kidney model was developed, accounting for the contribution of OATP4C1 and P-gp to digoxin renal secretion (Mikkaichi et al., 2004; Lee et al., 2014). Despite a large amount of available clinical plasma and urine concentration data for digoxin, the P-gp transporter kinetic parameter was practically nonidentifiable because of the lack of measured intracellular digoxin concentrations or sufficiently high temporal resolution of the urinary excretion rate data. As such, accuracy of the IVIVE approach for the P-gp REF parameter could not be assessed, consistent with previous efforts to model renal efflux transport of other drugs (Hsu et al., 2014; Posada et al., 2015). The developed model was therefore unsuitable for
A

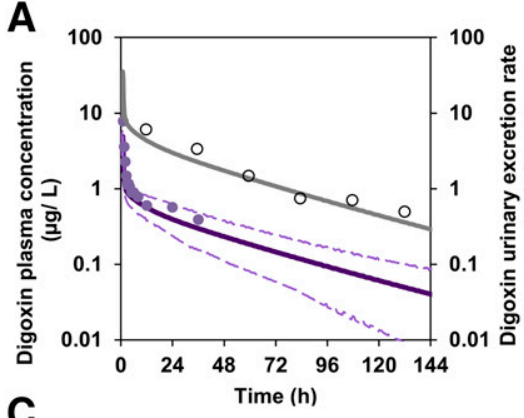

c

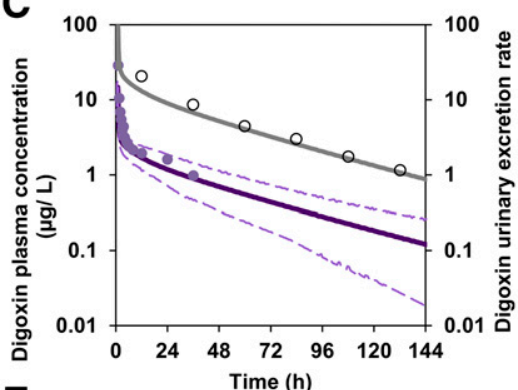

E

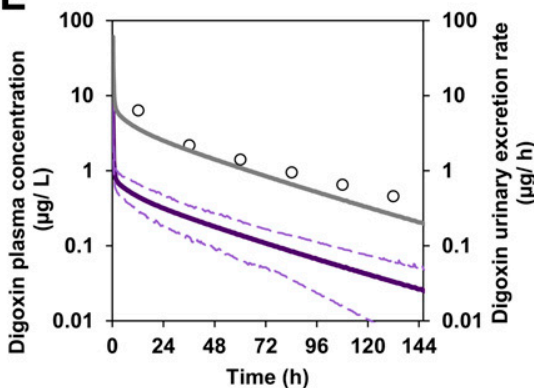

B
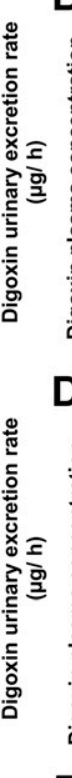

$F$

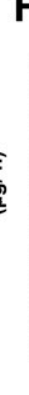

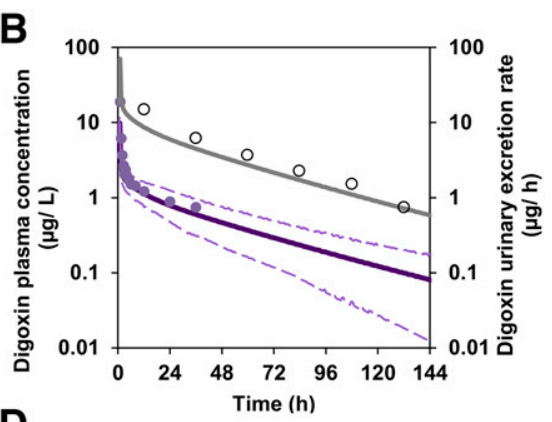
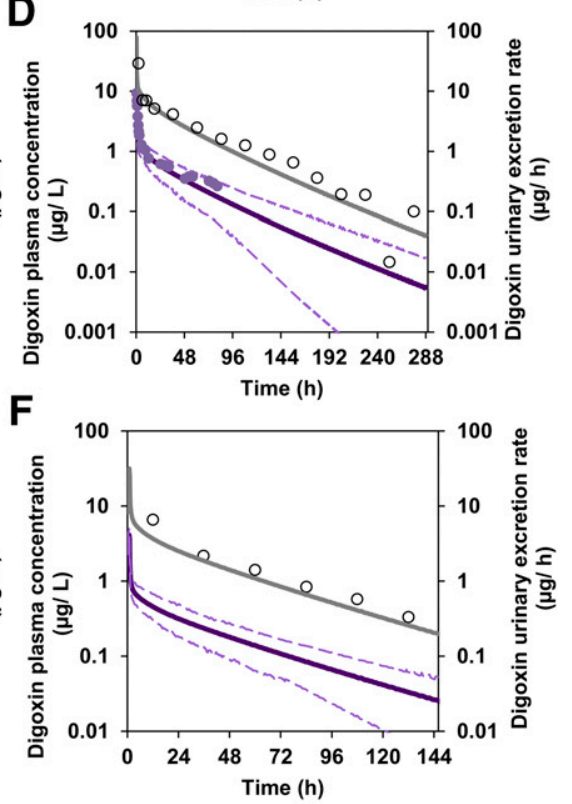

Fig. 5. Comparison of simulated and observed digoxin plasma concentration and urinary excretion rate profiles using SimCYP with MechKiM after $0.5 \mathrm{mg}$ by 1 hour infusion (Ochs et al., 1978)(A), $1 \mathrm{mg}$ by 1 hour infusion (Ochs et al., 1978)(B), $1.5 \mathrm{mg}$ by 1 hour infusion (Ochs et al., 1978)(C), $0.75 \mathrm{mg}$ by bolus injection (Johnson and Bye, 1975)(D), and urinary excretion profiles only after $0.4 \mathrm{mg}$ by bolus injection (Lindenbaum et al., 1981)(E) and $0.4 \mathrm{mg}$ by 1 hour infusion (Lindenbaum et al., 1981)(F). Mean (purple solid lines) and 5th and 95th percentiles (dashed purple line) of simulated plasma concentrations are overlaid with mean observed data (purple circles), whereas mean simulated urinary excretion rates (gray solid lines) are overlaid with mean observed data (open circle). 
TABLE 4

Simulated digoxin $\mathrm{CL}_{\mathrm{R}}$ and $\mathrm{AUC}_{0-\infty}$ parameters in different virtual populations

Each value represents the mean of 100 simulated individuals taken from the virtual population provided with the SimCYP simulator after a single $0.75 \mathrm{mg}$ i.v. dose.

\begin{tabular}{lcccc}
\hline \multicolumn{1}{c}{ Population } & $\begin{array}{c}\text { Simulated } \\
\mathrm{CL}_{\mathrm{R}}\end{array}$ & $\begin{array}{c}\% \text { of healthy } \\
\mathrm{CL}_{\mathrm{R}}\end{array}$ & $\begin{array}{c}\text { Simulated }_{\mathrm{AUC}_{0-\infty}} \\
\text { ml/min }\end{array}$ & $\begin{array}{c}\text { \% of healthy } \\
\mathrm{AUC}_{0-\infty}\end{array}$ \\
\hline Healthy & 131.9 & 100 & 3.36 & 100 \\
Elderly & 90.7 & 69 & 5.12 & 152 \\
$\begin{array}{c}\text { Moderate renal } \\
\text { impairment }\end{array}$ & 65.9 & 50 & 5.68 & 169 \\
$\begin{array}{c}\text { Severe renal } \\
\text { impairment }\end{array}$ & 43.8 & 33 & 7.00 & 208 \\
\hline
\end{tabular}

simulation of P-gp-mediated digoxin DDIs, although sensitivity analyses indicated that inhibition of renal P-gp would unlikely substantially affect digoxin plasma concentrations (Fig. 3), as proposed by Neuhoff et al. (2013b).

There was also insensitivity of digoxin AUC and $\mathrm{CL}_{R}$ to changes in $\mathrm{f}_{\mathrm{u} \text {,kidney,cell }}$ (Supplemental Fig. S3) because of very low $\mathrm{CL}_{\mathrm{PD}}$ relative to the active transport parameters. Changes to simulated unbound digoxin concentrations in the proximal tubule cells would affect the rate of digoxin diffusion back to the systemic circulation. However, because of low passive permeability, this change was marginal compared with uptake via active transport, and therefore $A U C$ and $\mathrm{CL}_{\mathrm{R}}$ were mostly unaffected.

Reliable estimate of the OATP4C1 $\mathrm{CL}_{\text {int,T }}$ could not be obtained based on reported in vitro transporter data and IVIVE scaling factors. Use of in vitro uptake transporter kinetic data from different literature sources resulted in approximately eight-fold difference in predicted $\mathrm{CL}_{\mathrm{R}}$ (Table 2). This finding further indicates the need for quality in vitro kinetic data and transporter abundance for in vitro systems and human kidney.

The weighted mean OATP4C1 $\mathrm{CL}_{\text {int,T }}$ obtained by fitting to clinical plasma concentration data were approximately half of the value obtained by using $\mathrm{CL}_{\mathrm{R}}$ data with a sensitivity analysis (Table 2). The resultant simulated digoxin $\mathrm{CL}_{\mathrm{R}}$ values were each within 1.5-fold of the observed value. The use of $\mathrm{CL}_{\mathrm{R}}$ data for optimization was viewed as more reliable because this approach focuses on the parameter of interest with less noise than when using plasma concentration data. Furthermore, separate fitting to mean plasma digoxin concentration data from individual studies was performed rather than global fitting, which can lead to bias in parameter estimation.

Nevertheless, sources of uncertainty of the optimized OATP4C1 $\mathrm{CL}_{\text {int,T }}$ parameter should be noted. First, the "optimal" $\mathrm{CL}_{\mathrm{R}}$ value used was obtained from a meta-analysis of clinical data from 19 studies (weighted mean $\mathrm{CL}_{\mathrm{R}}=136.1 \mathrm{ml} / \mathrm{min}$ ). This value differed slightly from those obtained in previous literature analyses [151.1 ml/min (Scotcher et al., 2016c) and $160.8 \mathrm{ml} / \mathrm{min}$ (Neuhoff et al., 2013b)], although in the current study some data were assigned for model evaluation. Second, the estimated OATP4C1 $\mathrm{CL}_{\text {int,T }}$ was dependent on the serum creatinine parameter (Fig. 4). Ideally the serum creatinine value would be informed by data obtained from subjects participating in the specific clinical studies, although in the current study, suitable data were missing in the majority of clinical study reports used in the $\mathrm{CL}_{\mathrm{R}}$ data analysis.
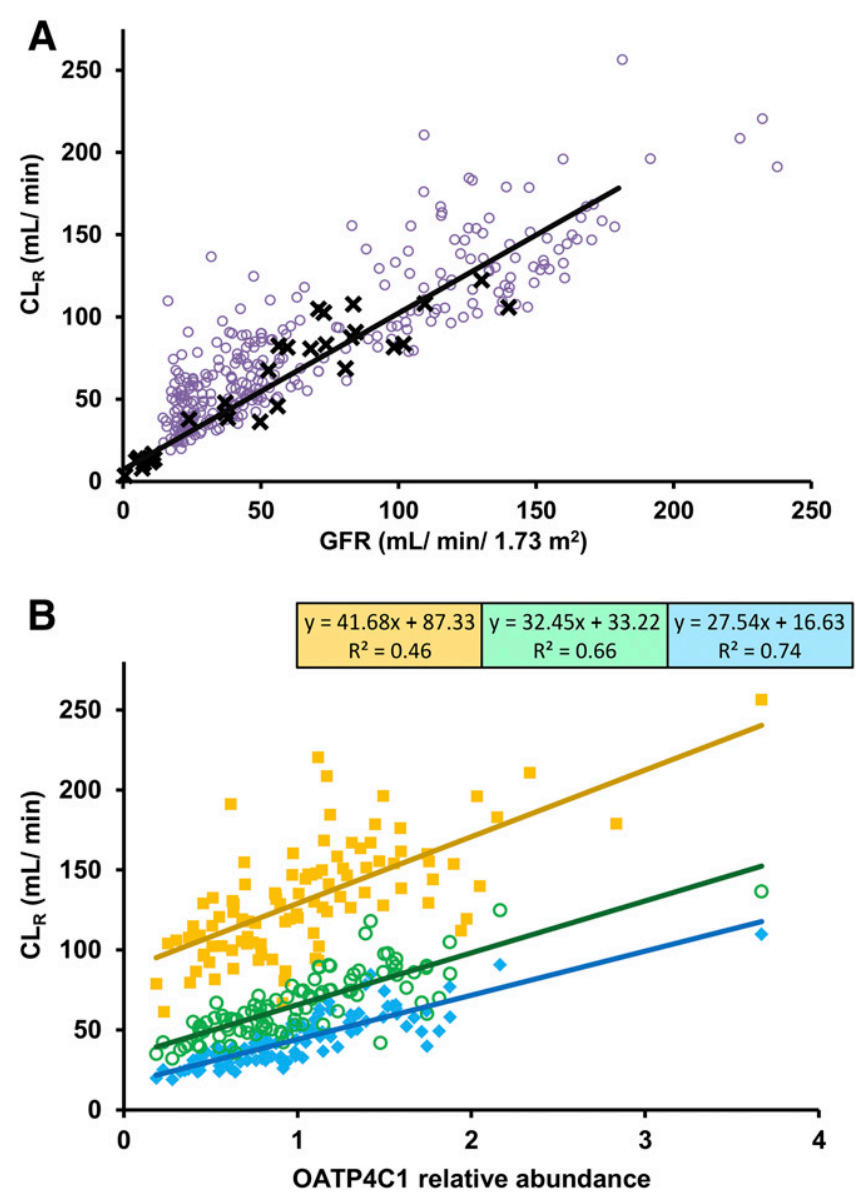

Fig. 6. Simulated $\mathrm{CL}_{\mathrm{R}}$ in comparison with GFR and OATP4C1 abundance in virtual populations. (A) Simulated $\mathrm{CL}_{\mathrm{R}}$ and GFR data (purple open circle) in healthy and moderate and severe renal impairment virtual subjects, in comparison with reported clinical data $\left(\mathrm{CL}_{\mathrm{CR}}\right.$ data on horizontal axis) (black X) (Bloom et al., 1966; Okada et al., 1978). Solid black line represents linear line of best fit using total least squares regression (which recognizes experimental error in both variables) for the observed clinical data. (B) Simulated $\mathrm{CL}_{\mathrm{R}}$ and GFR in healthy (yellow solid squares) and moderate (green open circles) and severe (turquoise solid diamond) renal impairment virtual subjects. Solid lines represent linear lines of best fit using ordinary least squares regression for data from each simulation, with relevant equations and $R^{2}$ shown in boxes.

Simulation of digoxin renal drug disposition in renal impairment: implications for drug toxicity. For drugs eliminated predominantly by renal excretion, dosage adjustment (e.g., for elderly patients or with impaired renal function) is informed by the ratio of the estimated GFR (eGFR) or $\mathrm{CL}_{\mathrm{CR}}$ in patients relative to subjects with normal renal function (Elinder et al., 2014). In the current study the difference in predicted digoxin $\mathrm{CL}_{\mathrm{R}}$ between elderly and young virtual subjects was smaller $(31 \%)$ than corresponding differences in simulated GFR [44\%; calculated using the Cockcroft-Gault equation (Cockcroft and Gault, 1976)], in agreement with the findings of a clinical study (Ewy et al., 1969). This supports the proposal that despite physiologic changes in kidney during aging (Darmady et al., 1973), proximal tubule secretion is largely retained in elderly subjects without kidney disease (Musso and Oreopoulos, 2011).

Dose adjustment in the clinic tends to use a reduction in renal plasma clearance by a ratio equivalent to the ratio of eGFR (or estimated $\mathrm{CL}_{\mathrm{CR}}$ ) in renally impaired patient compared with 

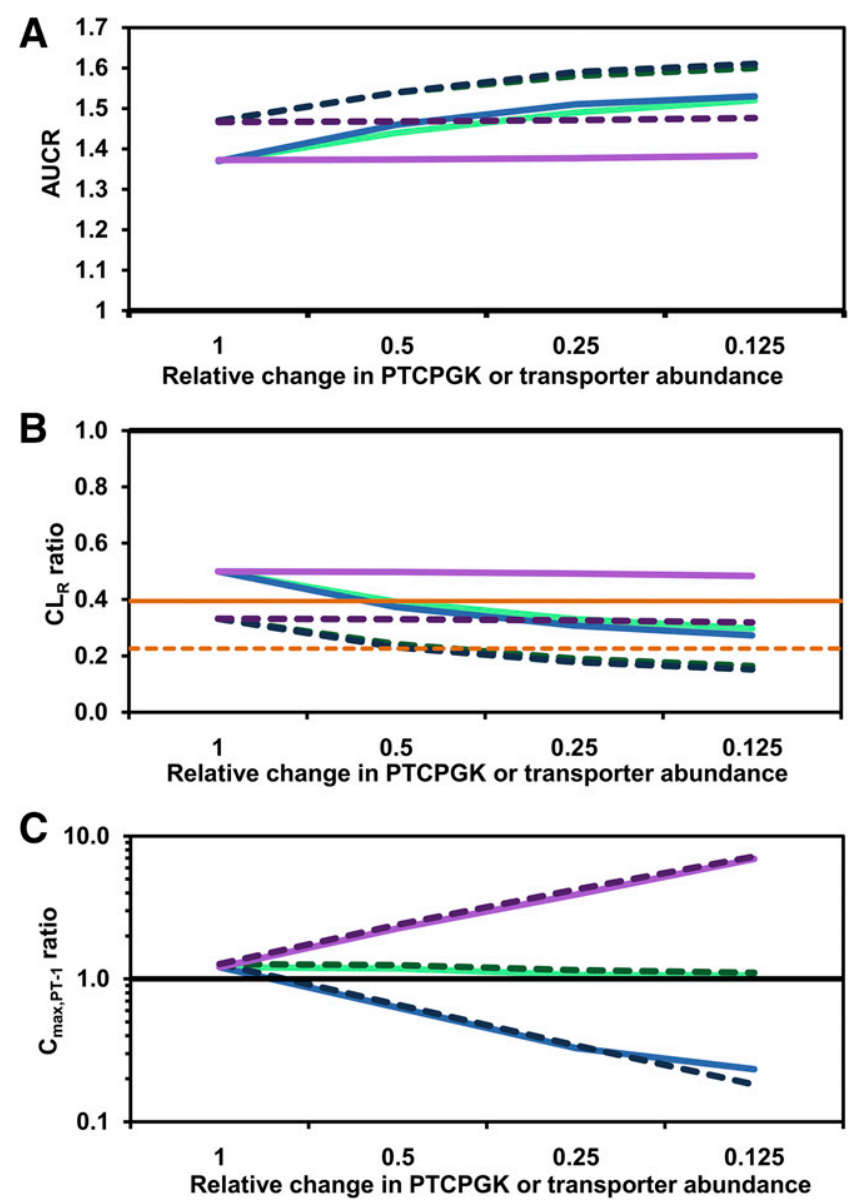

Fig. 7. Impact of reduced renal secretion on simulated digoxin AUC ratio (A), $\mathrm{CL}_{\mathrm{R}}(\mathrm{B})$ and $\mathrm{C}_{\max , \mathrm{PT}-1}$ ratio (C) in renal impairment populations. Renal secretion was reduced either by changing the kidney OATP4C1 or P-gp relative abundance parameters or by reducing the PTCPGK parameter by a proportional amount. Lines represent changes in PTCPGK in moderate renal impairment (light green solid line) and severe renal impairment (green dashed line), OATP4C1 abundance in moderate renal impairment (light blue solid line) and severe renal impairment (blue dashed line), and P-gp abundance in moderate renal impairment (light purple solid line) and severe renal impairment (purple dashed line). Each scenario was simulated in 100 virtual subjects. Solid horizontal black line (ratio $=1$ ) represents the healthy volunteer population; estimated $\mathrm{CL}_{\mathrm{R}}$ ratios for the average moderate $\left(\mathrm{GFR}=46.5 \mathrm{ml} / \mathrm{min} / 1.73 \mathrm{~m}^{2}\right.$; orange solid line) and severe (GFR $=23.5 \mathrm{ml} / \mathrm{min} / 1.73 \mathrm{~m}^{2}$; orange dashed line) renal impairment were calculated based on the correlation of GFR and $\mathrm{CL}_{\mathrm{R}}$ in the observed data (Bloom et al., 1966; Okada et al., 1978) (A). Relative change of PTCPGK or transporter abundance of 1 indicates that the default moderate or severe renal impairment population in the SimCYP simulator was used

patient with normal eGFR (Bloom et al., 1966; Okada et al., 1978). This assumes that all processes responsible for renal handling, including tubular secretion, decline in parallel with GFR (Bricker et al., 1960; Naud et al., 2011; Schnaper, 2014). As such, when active secretion occurs, mechanistic models that account only for changes in GFR cannot accurately simulate the decline in drug $\mathrm{CL}_{\mathrm{R}}$ (Grillo et al., 2012; Hsu et al., 2014; Li et al., 2014). A caveat is that simulated GFR values are sometimes necessarily and inappropriately compared with observed $\mathrm{CL}_{\mathrm{CR}}$ data (Bauer et al., 1982; Lin et al., 2013).

Various underlying physiological changes have been proposed to cause reduced tubular secretion in renal impairment, including transporter inhibition by uremic solutes, loss of proximal tubule cells, and decreases in transporter expression

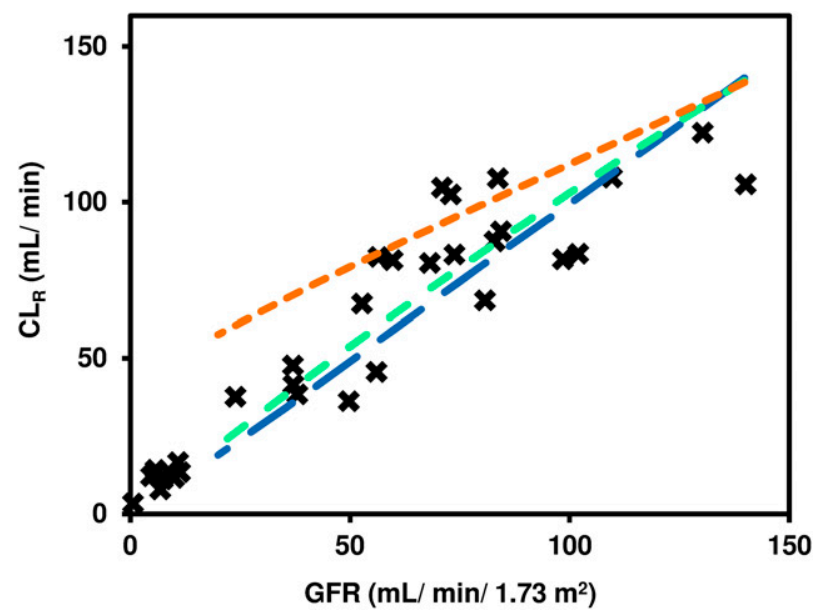

Fig. 8. Simulation of digoxin $\mathrm{CL}_{R}$ in population representative mode with changes in different systems parameters performed to represent changes in the case of renal impairment. Glomerular filtration rate (range $20-140 \mathrm{ml} / \mathrm{min} / 1.73 \mathrm{~m}^{2}$ ) was changed by altering the serum creatinine parameter (74.5-695.6 $\mu \mathrm{mol} / \mathrm{l})$; OATP4C1 abundance and PTCPGK parameters were altered by a factor proportional to the relative change in GFR from the population representative of the default "healthy volunteers" population $\left(\mathrm{GFR}=136.4 \mathrm{ml} / \mathrm{min} / 1.73 \mathrm{~m}^{2}\right.$; serum creatinine = $76.5 \mu \mathrm{mol} / \mathrm{l})$. Lines represent simulations performed with changes in GFR alone (orange dashed line), both GFR and OATP4C1 abundance (blue dashed line), or both GFR and PTCPGK (green dashed lines). Reported clinical data (black X) are overlaid (Bloom et al., 1966; Okada et al., 1978).

levels (Naud et al., 2011; Hsueh et al., 2016). Therefore, to mimic renal impairment, changes to transporter abundance (OATP4C1 and P-gp) per million proximal tubule cells and proximal tubule cellularity parameters of the model were considered in the current study. The effect of uremic toxins was not investigated due to limited availability of inhibition data. Equivalent changes to the OATP4C1 abundance or PTCPGK parameters had comparable impact on the predicted AUCR (e.g., reduction of either parameter by $50 \%$ in severe renal impairment resulted in $5 \%$ increase in AUCR) and $\mathrm{CL}_{R}$ ratio (e.g., reducing OATP4C1 abundance per million proximal tubule cells or PTCPGK by $50 \%$ in severe renal impairment resulted in $31 \%$ or $27 \%$ decrease in $\mathrm{CL}_{\mathrm{R}}$ ratio, respectively). The minor differences between changing OATP4C1 abundance and PTCPGK occurred because the PTCPGK parameter affects also tubular reabsorption, which is not affected by the OATP4C1 abundance parameter (see Methods). In contrast, changes in renal P-gp abundance per million proximal tubule cells had negligible effect on these pharmacokinetic parameters for digoxin (Fig. 7).

Conversely, simulated digoxin $\mathrm{C}_{\text {max,PT-1 }}$ was insensitive to changes in proximal tubule cell number but was affected by changes in the transporter abundance parameters (Fig. 7). Overall, the results show that the high degree of correlation between OATP4C1 abundance per million proximal tubule cells and PTCPGK with respect to effect on systemic exposure is not apparent when the dynamic situation within the proximal tubule cell is considered. Therefore, improved understanding of underlying mechanisms behind changes in tubular secretion in renally impaired patients is crucial to determine the increased risk of proximal tubule drug-related toxicity reported in such patients (Naughton, 2008) and for projecting the combined impact of multiple factors (e.g., transporter mediated DDIs in renally impaired subjects). 


\section{Conclusion}

A mechanistic kidney model for digoxin was developed accounting for the roles of OATP4C1 and P-gp in its tubular secretion and subsequently applied for the prediction of digoxin pharmacokinetics in special populations. Consideration of reduced GFR in renal impairment in isolation was insufficient to capture changes in digoxin $\mathrm{CL}_{R}$ in this patient group. Different mechanisms associated with reduced active tubular secretion in renal impairment were explored in the kidney model, namely reduced transporter abundance per million proximal tubule cells and decrease in proximal tubule cellularity. Although quantitative transporter abundance data in normal human kidney samples are emerging and are likely to become available for diseased tissue, data on proximal tubule cellularity in normal and diseased kidneys are lacking. Reduction in OATP4C1 expression or PTCPGK each caused comparable changes on the predicted digoxin systemic exposure and $\mathrm{CL}_{\mathrm{R}}$. In contrast, predicted proximal tubule concentration of digoxin was only sensitive to changes in the transporter expression parameters. These results suggest that depending on the output parameter of interest, accurate model specification of pathophysiology may or may not be important. However, the implications of potential misspecification could be more severe if the model developed is applied to extrapolate to more complex scenarios (e.g., transporter-mediated DDIs in renally impaired patients).

\section{Acknowledgments}

The authors acknowledge the assistance of Amir Khalifa and Sahar Fallaha for assistance with literature analyses and preliminary modelling and simulation efforts. The authors are grateful for the assistance of Eleanor Savill in preparing this manuscript.

\section{Authorship Contributions}

Participated in research design: Scotcher, Jones, Galetin, and Rostami-Hodjegan.

Conducted experiments: Scotcher.

Performed data analysis: Scotcher, Galetin, and RostamiHodjegan.

Wrote or contributed to the writing of the manuscript: Scotcher, Galetin, and Rostami-Hodjegan.

\section{References}

Andreucci M, Faga T, Pisani A, Sabbatini M, Russo D, and Michael A (2014) Prevention of contrast-induced nephropathy through a knowledge of its pathogenesis and risk factors. Sci World $J$ 2014:823169.

Bauer JH, Brooks CS, and Burch RN (1982) Clinical appraisal of creatinine clearance as a measurement of glomerular filtration rate. Am J Kidney Dis 2:337-346.

Bloom PM, Nelp WB, and Tuell SH (1966) Relationship of the excretion of tritiated digoxin to renal function. Am J Med Sci 251:133-144.

Bricker NS, Morrin PA, and Kime SW, Jr (1960) The pathologic physiology of chronic Bright's disease. An exposition of the "intact nephron hypothesis". Am J Med 28: 77-98.

Burt HJ, Neuhoff S, Almond L, Gaohua L, Harwood MD, Jamei M, RostamiHodjegan A, Tucker GT, and Rowland-Yeo K (2016) Metformin and cimetidine: Physiologically based pharmacokinetic modelling to investigate transporter mediated drug-drug interactions. Eur J Pharm Sci 88:70-82.

Cheng JW, Charland SL, Shaw LM, Kobrin S, Goldfarb S, Stanek EJ, and Spinler SA (1997) Is the volume of distribution of digoxin reduced in patients with renal dysfunction? Determining digoxin pharmacokinetics by fluorescence polarization immunoassay. Pharmacotherapy 17:584-590.

Chu XY, Bleasby K, Yabut J, Cai X, Chan GH, Hafey MJ, Xu S, Bergman AJ, Braun MP, Dean DC, et al. (2007) Transport of the dipeptidyl peptidase-4 inhibitor sitagliptin by human organic anion transporter 3 , organic anion transporting polypeptide 4C1, and multidrug resistance P-glycoprotein. J Pharmacol Exp Ther 321:673-683.

Cockcroft DW and Gault MH (1976) Prediction of creatinine clearance from serum creatinine. Nephron 16:31-41.

Darmady EM, Offer J, and Woodhouse MA (1973) The parameters of the ageing kidney. J Pathol 109:195-207.

Dave RA and Morris ME (2015) Quantitative structure-pharmacokinetic relationships for the prediction of renal clearance in humans. Drug Metab Dispos 43:73-81.
Ding R, Tayrouz Y, Riedel KD, Burhenne J, Weiss J, Mikus G, and Haefeli WE (2004) Substantial pharmacokinetic interaction between digoxin and ritonavir in healthy volunteers. Clin Pharmacol Ther 76:73-84.

Djuv A and Nilsen OG (2008) Caco-2 cell methodology and inhibition of the P-glycoprotein transport of digoxin by Aloe vera juice. Phytother Res 22:1623-1628.

Elinder C-G, Bárány P, and Heimbürger O (2014) The use of estimated glomerular filtration rate for dose adjustment of medications in the elderly. Drugs Aging 31: 493-499.

European Medicines Agency (2014) Guideline on the Evaluation of the Pharmacokinetics of Medicinal Products in Patients with Decreased Renal Function (CHMP/EWP/225/02). Committee for Human Medicinal Products, CHMP, London.

Ewy GA, Kapadia GG, Yao L, Lullin M, and Marcus FI (1969) Digoxin metabolism in the elderly. Circulation 39:449-453.

Fallon JK, Smith PC, Xia CQ, and Kim M-S (2016) Quantification of four efflux drug transporters in liver and kidney across species using targeted quantitative proteomics by isotope dilution nanoLC-MS/MS. Pharm Res 33:2280-2288.

Fossati L, Dechaume R, Hardillier E, Chevillon D, Prevost C, Bolze S, and Maubon N (2008) Use of simulated intestinal fluid for Caco-2 permeability assay of lipophilic drugs. Int $J$ Pharm 360:148-155.

Greiner B, Eichelbaum M, Fritz P, Kreichgauer H-P, von Richter O, Zundler J, and Kroemer HK (1999) The role of intestinal P-glycoprotein in the interaction of digoxin and rifampin. $J$ Clin Invest 104:147-153.

Grillo JA, Zhao P, Bullock J, Booth BP, Lu M, Robie-Suh K, Berglund EG, Pang KS, Rahman A, Zhang L, et al. (2012) Utility of a physiologically-based pharmacokinetic (PBPK) modeling approach to quantitatively predict a complex drug-drugdisease interaction scenario for rivaroxaban during the drug review process: implications for clinical practice. Biopharm Drug Dispos 33:99-110.

Halkin H, Sheiner LB, Peck CC, and Melmon KL (1975) Determinants of the renal clearance of digoxin. Clin Pharmacol Ther 17:385-394.

He J, Yu Y, Prasad B, Chen X, and Unadkat JD (2014) Mechanism of an unusual, but clinically significant, digoxin-bupropion drug interaction. Biopharm Drug Dispos 35:253-263.

Hilgendorf C, Ahlin G, Seithel A, Artursson P, Ungell AL, and Karlsson J (2007) Expression of thirty-six drug transporter genes in human intestine, liver, kidney, and organotypic cell lines. Drug Metab Dispos 35:1333-1340.

Hsu V, de L T Vieira M, Zhao P, Zhang L, Zheng JH, Nordmark A, Berglund EG, Giacomini KM, and Huang SM (2014) Towards quantitation of the effects of renal impairment and probenecid inhibition on kidney uptake and efflux transporters, using physiologically based pharmacokinetic modelling and simulations. Clin Pharmacokinet 53:283-293.

Hsueh C-H, Yoshida K, Zhao P, Meyer TW, Zhang L, Huang S-M, and Giacomini KM (2016) Identification and quantitative assessment of uremic solutes as inhibitors of renal organic anion transporters, OAT1 and OAT3. Mol Pharm 13:3130-3140.

Jadhav PR, Cook J, Sinha V, Zhao P, Rostami-Hodjegan A, Sahasrabudhe V, Stockbridge N, and Powell JR (2015) A proposal for scientific framework enabling specific population drug dosing recommendations. $J$ Clin Pharmacol 55: 1073-1078.

Jamei M, Marciniak S, Edwards D, Wragg K, Feng K, Barnett A, and RostamiHodjegan A (2013) The simcyp population based simulator: architecture, implementation, and quality assurance. In Silico Pharmacol 1:9

Jamei M, Marciniak S, Feng K, Barnett A, Tucker G, and Rostami-Hodjegan A (2009) The Simcyp population-based ADME simulator. Expert Opin Drug Metab Toxicol 5: 211-223.

Johnson BF and Bye C (1975) Maximal intestinal absorption of digoxin, and its relation to steady state plasma concentration. Br Heart $J$ 37:203-208.

Jones HM, Chen Y, Gibson C, Heimbach T, Parrott N, Peters SA, Snoeys J, Upreti VV, Zheng M, and Hall SD (2015) Physiologically based pharmacokinetic modeling in drug discovery and development: a pharmaceutical industry perspective. Clin Pharmacol Ther 97:247-262.

Jusko WJ and Weintraub M (1974) Myocardial distribution of digoxin and renal function. Clin Pharmacol Ther 16:449-454.

Koup JR, Greenblatt DJ, Jusko WJ, Smith TW, and Koch-Weser J (1975) Pharmacokinetics of digoxin in normal subjects after intravenous bolus and infusion doses. $J$ Pharmacokinet Biopharm 3:181-192.

Kramer WG, Kolibash AJ, Lewis RP, Bathala MS, Visconti JA, and Reuning RH (1979) Pharmacokinetics of digoxin: relationship between response intensity and predicted compartmental drug levels in man. J Pharmacokinet Biopharm 7:47-61.

Lee CA, Kalvass JC, Galetin A, and Zamek-Gliszczynski MJ (2014) ITC commentary on the prediction of digoxin clinical drug-drug interactions from in vitro transporter assays. Clin Pharmacol Ther 96:298-301.

Li J, Kim S, Sha X, Wiegand R, Wu J, and LoRusso P (2014) Complex disease-, gene-, and drug-drug interactions: impacts of renal function, CYP2D6 phenotype, and OCT2 activity on veliparib pharmacokinetics. Clin Cancer Res 20:3931-3944.

Lin YC, Bansal N, Vittinghoff E, Go AS, and Hsu CY (2013) Determinants of the creatinine clearance to glomerular filtration rate ratio in patients with chronic kidney disease: a cross-sectional study. BMC Nephrol 14:268.

Lindenbaum J, Long R, Wenger T, Mallis G, and Cato A (1981) Lack of difference in digoxin urinary excretion with two intravenous infusion rates. Clin Pharmacol Ther 30:317-320.

Matzke GR, Aronoff GR, Atkinson AJ, Jr, Bennett WM, Decker BS, Eckardt K-U, Golper T, Grabe DW, Kasiske B, Keller F, et al. (2011) Drug dosing consideration in patients with acute and chronic kidney disease-a clinical update from Kidney Disease: Improving Global Outcomes (KDIGO). Kidney Int 80:1122-1137.

Mikkaichi T, Suzuki T, Onogawa T, Tanemoto M, Mizutamari H, Okada M, Chaki T, Masuda S, Tokui T, Eto N, et al. (2004) Isolation and characterization of a digoxin transporter and its rat homologue expressed in the kidney. Proc Natl Acad Sci USA 101:3569-3574

Musso CG and Oreopoulos DG (2011) Aging and physiological changes of the kidneys including changes in glomerular filtration rate. Nephron, Physiol 119 (Suppl 1): $1-5$. 
Nangaku M (2006) Chronic hypoxia and tubulointerstitial injury: a final common pathway to end-stage renal failure. J Am Soc Nephrol 17:17-25.

Naud J, Michaud J, Beauchemin S, Hébert M-J, Roger M, Lefrancois S, Leblond FA, and Pichette V (2011) Effects of chronic renal failure on kidney drug transporters and cytochrome P450 in rats. Drug Metab Dispos 39:1363-1369.

Naughton CA (2008) Drug-induced nephrotoxicity. Am Fam Physician 78:743-750.

Neuhoff S, Gaohua L, Burt H, Jamei M, Li L, Tucker GT, and Rostami-Hodjegan A (2013a) Accounting for transporters in renal clearance: towards a mechanistic kidney model (Mech KiM), in Transporters in Drug Development (Sugiyama Y and Steffansen B, eds) pp 155-177, Springer, New York.

Neuhoff S, Ungell A-L, Zamora I, and Artursson P (2003) pH-dependent bidirectional transport of weakly basic drugs across Caco-2 monolayers: implications for drugdrug interactions. Pharm Res 20:1141-1148.

Neuhoff S, Yeo KR, Barter Z, Jamei M, Turner DB, and Rostami-Hodjegan A (2013b) Application of permeability-limited physiologically-based pharmacokinetic models: part I-digoxin pharmacokinetics incorporating P-glycoprotein-mediated efflux. $J$ Pharm Sci 102:3145-3160.

Neuhoff S, Yeo KR, Barter Z, Jamei M, Turner DB, and Rostami-Hodjegan A (2013c) Application of permeability-limited physiologically-based pharmacokinetic models: part II - prediction of P-glycoprotein mediated drug-drug interactions with digoxin. $J$ Pharm Sci 102:3161-3173.

Ochs HR, Greenblatt DJ, Bodem G, and Harmatz JS (1978) Dose-independent pharmacokinetics of digoxin in humans. Am Heart $J$ 96:507-511.

Okada RD, Hager WD, Graves PE, Mayersohn M, Perrier DG, and Marcus FI (1978) Relationship between plasma concentration and dose of digoxin in patients with and without renal impairment. Circulation 58:1196-1203.

Posada MM, Bacon JA, Schneck KB, Tirona RG, Kim RB, Higgins JW, Pak YA, Hall SD, and Hillgren KM (2015) Prediction of renal transporter mediated drug-drug interactions for pemetrexed using physiologically based pharmacokinetic modeling. Drug Metab Dispos 43:325-334.

Prasad B, Johnson K, Billington S, Lee C, Chung GW, Brown CD, Kelly EJ, Himmelfarb J, and Unadkat JD (2016) Abundance of drug transporters in the human kidney cortex as quantified by quantitative targeted proteomics. Drug Metab Dispos 44:1920-1924 $10.1124 /$ dmd 116.072066.

Rengelshausen J, Göggelmann C, Burhenne J, Riedel KD, Ludwig J, Weiss J, Mikus G, Walter-Sack I, and Haefeli WE (2003) Contribution of increased oral bioavailability and reduced nonglomerular renal clearance of digoxin to the digoxinclarithromycin interaction. Br J Clin Pharmacol 56:32-38.

Richardson JC, Scalera V, and Simmons NL (1981) Identification of two strains of MDCK cells which resemble separate nephron tubule segments. Biochim Biophys Acta 673:26-36.

Rodgers T, Leahy D, and Rowland M (2005) Physiologically based pharmacokinetic modeling 1: predicting the tissue distribution of moderate-to-strong bases. $J$ Pharm Sci 94:1259-1276.

Rodgers T and Rowland M (2006) Physiologically based pharmacokinetic modelling 2 predicting the tissue distribution of acids, very weak bases, neutrals and zwitterions. J Pharm Sci 95:1238-1257.

Rostami-Hodjegan A (2012) Physiologically based pharmacokinetics joined with in vitro-in vivo extrapolation of ADME: a marriage under the arch of systems pharmacology. Clin Pharmacol Ther 92:50-61.

Rowland M, Peck C, and Tucker G (2011) Physiologically-based pharmacokinetics in drug development and regulatory science. Annu Rev Pharmacol Toxicol 51:45-73.

Rowland Yeo K, Aarabi M, Jamei M, and Rostami-Hodjegan A (2011) Modeling and predicting drug pharmacokinetics in patients with renal impairment. Expert Rev Clin Pharmacol 4:261-274.

Sayama H, Takubo H, Komura H, Kogayu M, and Iwaki M (2014) Application of a physiologically based pharmacokinetic model informed by a top-down approach for the prediction of pharmacokinetics in chronic kidney disease patients. AAPS $J$ 16:1018-1028.

Schnaper HW (2014) Remnant nephron physiology and the progression of chronic kidney disease. Pediatr Nephrol 29:193-202.

Scotcher D, Jones C, Posada M, Galetin A, and Rostami-Hodjegan A (2016a) Key to opening kidney for in vitro-in vivo extrapolation entrance in health and disease: Part II: Mechanistic models and in vitro-in vivo extrapolation. AAPS $J$ 18: 1082-1094.

Scotcher D, Jones C, Posada M, Rostami-Hodjegan A, and Galetin A (2016b) Key to opening kidney for in vitro-in vivo extrapolation entrance in health and disease Part I: In vitro systems and physiological Data. AAPS J 18:1067-1081.

Scotcher D, Jones C, Rostami-Hodjegan A, and Galetin A (2016c) Novel minimal physiologically-based model for the prediction of passive tubular reabsorption and renal excretion clearance. Eur J Pharm Sci 94:59-71.

Steiness E (1974) Renal tubular secretion of digoxin. Circulation 50:103-107.

Steiness E, Waldorff S, and Hansen PB (1982) Renal digoxin clearance: dependence on plasma digoxin and diuresis. Eur J Clin Pharmacol 23:151-154.

Tanigawara Y, Okamura N, Hirai M, Yasuhara M, Ueda K, Kioka N, Komano T, and Hori R (1992) Transport of digoxin by human P-glycoprotein expressed in a porcine kidney epithelial cell line (LLC-PK1). J Pharmacol Exp Ther 263: $840-845$.

Troutman MD and Thakker DR (2003) Efflux ratio cannot assess P-glycoproteinmediated attenuation of absorptive transport: asymmetric effect of P-glycoprotein on absorptive and secretory transport across Caco-2 cell monolayers. Pharm Res 20:1200-1209.

US Food Drug Admin (2010) Guidance for Industry:Pharmacokinetics in Patients with Impaired Renal Function-Study Design, Data Analysis, and Impact on Dosing and Labeling (Revision 1), US Food and Drug Administration, Silver Spring, MD.

Varma MV, Lin J, Bi YA, Kimoto E, and Rodrigues AD (2015) Quantitative rationalization of gemfibrozil drug interactions: consideration of transporters-enzyme interplay and the role of circulating metabolite gemfibrozil 1-O- $\beta$-glucuronide. Drug Metab Dispos 43:1108-1118.

Wagner C, Zhao P, Pan Y, Hsu V, Grillo J, Huang SM, and Sinha V (2015) Application of physiologically based pharmacokinetic (PBPK) modeling to support dose selection: Report of an FDA public workshop on PBPK. CPT Pharmacometrics Syst Pharmacol 4:226-230.

Wang L and Sweet DH (2013) Renal organic anion transporters (SLC22 family): expression, regulation, roles in toxicity, and impact on injury and disease. AAPS J 15:53-69.

Wang X, Bonventre JV, and Parrish AR (2014) The aging kidney: increased susceptibility to nephrotoxicity. Int $J$ Mol Sci 15:15358-15376.

Zamek-Gliszczynski MJ, Lee CA, Poirier A, Bentz J, Chu X, Ellens H, Ishikawa T, Jamei M, Kalvass JC, Nagar S, et al.; International Transporter Consortium (2013) ITC recommendations for transporter kinetic parameter estimation and translational modeling of transport-mediated PK and DDIs in humans. Clin Pharmacol Ther 94:64-79.

Zhang S and Morris ME (2003) Effect of the flavonoids biochanin A and silymarin on the P-glycoprotein-mediated transport of digoxin and vinblastine in human intestinal Caco-2 cells. Pharm Res 20:1184-1191.

Address correspondence to: Amin Rostami-Hodjegan, Centre for Applied Pharmacokinetic Research, Manchester Pharmacy School, University of Manchester, Stopford Building, Oxford Road, Manchester, M13 9PT, UK. E-mail: amin.rostami@manchester.ac.uk 